\title{
GEOQUÍMICA DE PARTE DO COMPLEXO GRANULÍTICO DE SANTA CATARINA, BRASIL MERIDIONAL: UMA SUÍTE CÁLCIO-ALCALINA ANTIGA FORMADA POR DIFERENCIAÇÃO DE BASALTO ALUMINOSO
}

\author{
M.C.H.Figueiredo (in memorian) ${ }^{1}$, I.McReath ${ }^{1}$, M.A.S.Basei ${ }^{1}$, M.S.M.Mantovani ${ }^{2}$
}

O complexo granulítico de Santa Catarina é composto por várias séries (Lameyre \& Bowden, 1982) de metaígneas toleiítica a cálcio-alcalinas. Idades radiométricas calculadas pelo método $\mathrm{K}-\mathrm{Ar}$ em minerais da paragênese de alto grau, pelas isócronas $\mathrm{Rb}-\mathrm{Sr}$ em rocha total (Hartmann et al., 1979; Basei, 1985; Siga Jr., 1995) e por idades U-Pb em zircão (Basei, 1985) recaem na faixa de 2,83 a $2,4 \mathrm{Ga}$, e representam idades mínimas para a formação dos protólitos. Razões $\left({ }^{87} \mathrm{Sr} /{ }^{86} \mathrm{Sr}\right)$ iniciais variam desde 0,701 a 0,704 , e atestam para a natureza primitiva de algumas das rochas. Idades transamazônicas $(2,3-1,9 \mathrm{Ga})$ também foram obtidas pelos métodos $\mathrm{K}-\mathrm{Ar}$ (mineral), U-Pb (zircão), e por isócronas $\mathrm{Rb}-\mathrm{Sr}$ (rocha total) e $\mathrm{Pb}-\mathrm{Pb}$ (rocha total), e foram interpretadas como as idades do último evento de metamorfismo de grau elevado, associado à uma fase de migmatização.

Foram obtidos novos dados geoquímicos para uma associação noríticotonalítico-granodioritico que porta enclaves de norito e piroxenito, e aflora entre as cidades de Luiz Alves e Barra Velha. Embora amostras já analisadas (Moreira \& Marimon, 1980; Hartmann, 1981, 1988; Marques, 1988; Siga Jr., 1995) possam não ser cogenéticas com as rochas da região Luiz Alves - Barra Velha, é possivel que fossem produzidas por processos genéticos semelhantes.

Clinopiroxenitos e websteritos (asteriscos e cruzes diagonais para dados novos e já publicados, respectivamente) possuem as características geoquímicas de cumulatos praticamente puros, formados ao longo da cristalização fracionada de um magma máfico. A suíte de noritos a charnockitos conforma-se às tendências ígneas de Beswick \& Soucie (1978), e define arranjos lineares em muitos diagramas Harker. Definimos, assim, a tendência principal da suite, talvez uma linha de ascendência líquida, que inclui noritos com teores altos de $\mathrm{Al}_{2} \mathrm{O}_{3}$ $(\sim 17 \%)$. Por outro lado, alguns exemplos de noritos apresentam elevados teores de $\mathrm{Fe}$, ficando em desconformidade com a tendência principal. Tais rochas podem ser cumulatos de minerais ferromagnesianos. Algumas análises já publicadas apresentam teores muito altos de $\mathrm{Al}$, condizentes com uma origem através da acumulação de plagioclásio. A separação física de fases cumuláticas de densidades diferentes, ambas derivadas de um magma basáltico, é possivel sob altas pressões, correspondentes às da base da crosta continental. Nota-se que algumas outras rochas possuem baixos teores de $\mathrm{Al}$, relativo à tendência principal, embora não sejam notadamente mais ricas em Fe. Tais rochas podem representar a contraparte das de teores muito altos de $\mathrm{Al}$.

No diagrama $R_{1}-R_{2}$ (La Roche et al., 1980), as rochas são classificadas como gabro, tonalito e granodiorito, constituindo-se em uma suite semelhante à série cálcio-alcalina pré-colisional moderna (Batchelor \& Bowden, 1985). No diagrama FMA algumas rochas máficas

\footnotetext{
${ }^{1}$ DGG, Instituto de Geociências, Universidade de São Paulo.

${ }^{2}$ Instituto Astronômico e Geofisico, Universidade de São Paulo.
} 
aparentam ser toleiíticas, embora tal característica seja essencial para cumulatos associados à série cálcio-alcalina, para que haja evolução da parte intermediária-félsica da suite sem enriquecimento em Fe.

As rochas da tendência principal têm teores baixos de $\mathrm{Rb}, \mathrm{Th}, \mathrm{U}, \mathrm{Nb}$ e Ta, e teores altos de $\mathrm{Sr}, \mathrm{Ba}, \mathrm{LREE}$ e $\mathrm{Nd}$. No diagrama $\mathrm{Nb}-\mathrm{Y}$ as rochas mais félsicas ocupam o campo dos granitóides de arcos vulcânicos modernos. Diagramas multi-elementos, com normalização para o manto primitivo revelam empobrecimento de $\mathrm{Ta}, \mathrm{Nb}$ e $\mathrm{Ti}$, uma característica comum, porém não exclusiva, de rochas cálcio-alcalinas modernas, uma vez que foi encontrada, também, em rochas arqueanas lewisianas. As rochas lewisianas apresentam, também, empobrecimento de $\mathrm{Rb}, \mathrm{Th}, \mathrm{U}$ e K, relativo a rochas cálcio-alcalinas modernas.

Através do comportamento contrastado de elementos compativeis (por exemplo, $\mathrm{Ni}$ ) e incompativeis (por exemplo, $\mathrm{Zr}$ ), demonstra-se que a cristalização fracionada de um magma máfico é o processo petrogenético mais provável para a formação da tendência principal, e que as composições dos piroxenitos convergem em direção à composição provável do magma progenitor, o que confirma sua origem como cumulatos cogenéticos. Modelamento por passos seqüenciais do processo por XLFRAC (Stormer Jr. \& Nicholls, 1978) partiu da composição do progenitor e passou por etapas intermediárias, todas definidas a partir dos diagramas Harker. Composições apropriadas dos minerais fracionados foram escolhidas das apresentadas por Deer et al. (1963), simulando-se a tendência de Bowen para a evolução das composições. A partir de um basalto aluminoso, a separação inicial de olivina-gabro ou gabronorito, esta com titanomagnetita acessória traz a composição do magma diferenciado à dos noritos mais félsicos. A seguir, a separação de leucogabro ou leucogabro-norito, ambos com minerais óxidos de $\mathrm{Fe}-\mathrm{Ti}$ acessórios, leva o diferenciado até os enderbitos. $\mathbf{0}$ modelo prevê a produção de uma suíte predominantemente máfica (50-60\% de peso), com $28-35 \%$ de peso de rochas com de $\sim 54 \%$ até $\sim 64 \%$ de $\mathrm{SiO}_{2}$. Essas proporções conformam-se às observações de campo na região, e assemelham-se às modeladas para a evolução, sob condições sub-saturadas em água, de rochas extrusivas cálcio-alcalinas modernas a partir de basalto de alto-Al (por exemplo, McReath, 1972).

Rochas intermediárias de suites cálcio-alcalinas arqueanas podem ser formadas durante subduç̧ão pela fusão parcial de crosta oceânica enquanto, nas suites modernas formam-se através da cristalização fracionada de magma basáltico gerado por um processo mais complexo. Exceções ocorrem quando a crosta oceânica nova e quente sofre fusão parcial durante subducção em algumas situações modernas (Defant \& Drummond, 1990). Propomos que no Arqueano, um processo "moderno" de desidratação da placa em subducção, seguida por invasão do manto sobrejacente e fusão parcial deste com produção de magma basáltico, teria ocorrido. Este magma submetido à cristalização fracionada pode produzir uma suíte cálcio-alcalina dominada por termos máficos. Isso ocorreria se as bacias oceânicas formadas tivessem sido amplas o bastante para que a crosta oceânica se tornasse fria e hidratada.

Agradecemos a B.J.Fryer e a O. Siga Jr. pelas discussões proveitosas.

\section{Referências Bibliográficas}

BATCHELOR, R.A.; BOWDEN, P. (1985) Petrogenetic interpretation of granitic rocks series using multicationic parameters. Chemical Geology, v.48, p.43-55.

BASEI, M. (1985) O cinturão Dom Feliciano em Santa Catarina São Paulo, 190p. (TeseDoutorado) - Instituto de Geociências, Universidade de São Paulo.

BESWICK, A.E.; SOUCIE, G. (1978) A correction procedure for metasomatism in an Archean greenstone belt. Precambrian Research, v.6, p.235-248. 
DEER, W.A.; HOWIE, R.; ZUSSMAN, J. (1963) Rock Forming Minerals, London, Longmans, v.1-5.

DEFANT, M.J.; DRUMMOND, M.S. (1990) Derivation of some modern arc magmas by melting of young subducted lithosphere. Nature, v.347, p.662-665.

HARTMANN, L. (1981) Petrogênese dos granulitos e ultramafitos de Luiz Alves (SC). Porto Alegre, 104p. (Tese - Doutorado) - Universidade Federal do Rio Grande do Sul.

HARTMANN, L. (1988) Geoquímica de terras raras e geotermobarometria de granulitos de Dom Pedrito e Luiz Alves, no extremo sul do Brasil. Geochimica Brasiliensis, v.2, p.1-14.

HARTMANN, L.A.; SILVA, L.C.; ORLANDI, V. (1979) O Complexo Granulítico de Santa Catarina. Acta Geologica Leopoldensia , v.6, p.94-112.

LAMEYRE, J.; BOWDEN, P. (1982) Journal of Volcanology and Geothermal Research, v.14, p.169-186.

LA ROCHE, H.; LETERRIER, J.; GRANCLAUDE, P.; MARCHAL, M. (1980) A classification of volcanic and plutonic rocks using R1-R2 diagrams and major element analysers: its relationship with current nomenclature. Chemical Geology, v.29, p.183-210.

MARQUES, L.S. (1988) Caracterização geoquímica das rochas vulcânicas da Bacia do Paraná: implicações petrogenéticas. São Paulo, 175p. (Tese - Doutorado) - Instituto de Geociências, Universidade de São Paulo.

McREATH, I. (1972) Petrogenesis in island arcs. England, 110p. (Tese - Doutorado) - Leeds University.

MOREIRA, M.L.O.; MARIMON, M.P. (1980) Ensaio petrográfico e petroquímico das rochas do fácies granulito. Complexo granulítico de Santa Catarina, Folha SC-22ZB. In: CONGRESSO BRASILEIRO DE GEOLOGIA, 31., Camboriú, 1980. Anais. Camboriú, SBG, v.4, p.2119-2133.

PEARCE, J.A.; HARRIS, N.B.W.; TINDLE, A.G. (1984) Trace element discrimination diagrams for the tectonic interpretation of granitic rocks. Journal of Petrology, v.25, p.956-982.

SIGA JR., O. (1995) Domínios tectônicos do Sudeste do Paraná e Nordeste de Santa Catarina: Geocronologia e Evolução Crustal. São Paulo, 212p. (Tese - Doutorado) Instituto de Geociências, Universidade de São Paulo.

STORMER JR., J.; NICHOLLS, L. (1978) XLFRAC: a program for the interactive texting of magmatic differentiation models. Computers \& Geosciences, v.4, p.143-159. 